observada en mujeres premenopáusicas entre el IMC y el riesgo de cáncer de mama, el más frecuente en estas mujeres. Según los resultados y los estimados actuales del IMC en las mujeres del Reino Unido, se estimó que 5\% de todos los casos de cáncer en mujeres posmenopáusicas de ese país están asociados con el sobrepeso o la obesidad (IMC $\geq 25)$ y que $4 \%$ están asociados con la obesidad (IMC $\geq 30$ ). En el caso del cáncer de endometrio y del adenocarcinoma de esófago, el IMC representa el principal factor de riesgo modificable.

Estos resultados constituyen la primera evidencia científica de la asociación entre el IMC y muchos de estos tipos de cáncer y el gran tamaño de la muestra le aporta una considerable robustez a estas conclusiones. En la Región de las Américas, donde el sobrepeso y la obesidad constituyen un grave y creciente problema, estos resultados deben tomarse muy en cuenta, tanto por los especialistas como por las autoridades de salud. (Reeves GK, Pirie K, Beral V, Green J, Spencer E, Bull D. Cancer incidence and mortality in relation to body mass index in the Million Women Study: cohort study. Br Med J. 2007; 335:1134.)

\section{Exposición al cadmio e hipertensión arterial en adultos fumadores y no fumadores}

El cadmio es un metal tóxico y carcinogénico de amplia distribución en la naturaleza. Las principales fuentes de exposición al cadmio en la población general son el humo del cigarro, el consumo de algunos alimentos y el aire ambiental, especialmente en zonas urbanas y en las proximidades de plantas industriales. La exposición al cadmio produce hipertensión en modelos animales, sin embargo los estudios epidemiológicos para determinar la asociación entre la exposición al cadmio ambiental y la tensión arterial en las personas no son concluyentes.

En este trabajo se investigó la asociación entre los niveles de cadmio en la sangre y la orina, por una parte, y la tensión arterial y la prevalencia de la hipertensión, por la otra, en una muestra representativa de los adultos de los Estados Unidos de América. El contenido de cadmio, tanto en la orina como en la sangre, es un marcador de la exposición prolongada o actual a ese metal, aunque los niveles en la sangre reflejan mejor la exposición reciente que los niveles en la orina.

Para este estudio se analizaron las concentraciones de cadmio en la sangre de 10991 personas y de cadmio en la orina de 3496 personas, del total de 15332 estadounidenses no institucionalizados de 20 años de edad o más participantes en la Encuesta Nacional de Salud y Nutrición (NHANES) de 1999-2004.

Las medias geométricas de la concentración de cadmio en la sangre y en la orina fueron 3,77 $\mathrm{nmol} / \mathrm{L}$ y 2,46 nmol/L, respectivamente. Después de ajustar por múltiples variables, las diferencias promedio de la tensión arterial sistólica entre el percentil 90 y el percentil 10 de la distribución de las concentraciones de cadmio en la sangre fue de 1,36 $\mathrm{mm} \mathrm{Hg}$ (intervalo de confianza de 95\% [IC95\%]: $-0,28$ a 3,00) y de cadmio en la orina de 1,68 $\mathrm{mm} \mathrm{Hg}$ (IC95\%: 0,57 a 2,78).

La asociación de las concentraciones de cadmio en la sangre y la orina y la tensión arterial fueron muy similares en hombres y mujeres, y no se observó ningún tipo de interacción significativa. Según su clasificación como fumadores, las diferencias promedio entre la tensión arterial sistólica y diastólica de los participantes ubicados en el percentil 90 por sus niveles de cadmio con respecto a los del percentil 10 fueron: 2,35 mm $\mathrm{Hg}$ y 3,27 mm $\mathrm{Hg}$, respectivamente, entre los que nunca fumaron; $1,69 \mathrm{~mm} \mathrm{Hg}$ y 1,55 mm Hg entre los ex fumadores; y $0,02 \mathrm{~mm} \mathrm{Hg}$ y $0,69 \mathrm{~mm} \mathrm{Hg}$ entre los fumadores activos. Las variaciones en la asociación entre los niveles de cadmio en la sangre y la tensión arterial sistólica y diastólica de los fumadores activos en comparación con los que nunca fumaron fueron significativas. Para los niveles de cadmio en la orina, esta asociación fue similar en todos los subgrupos de fumadores y no fumadores. No se encontró asociación entre el nivel de cadmio en la orina y la tensión arterial, o entre los niveles de cadmio en la sangre y la orina y la prevalencia de hipertensión.

A pesar del bajo nivel de exposición al cadmio observado en esta muestra representativa de la población adulta estadounidense, se encontró una ligera pero positiva asociación entre los niveles de cadmio en la sangre y la tensión arterial. Esta asociación fue más fuerte en las personas que nunca fumaron, intermedia en los ex fumadores y baja o nula en los fumadores. Deben emprenderse investigaciones similares en otros escenarios de la Región, donde la contaminación con cadmio puede ser mucho mayor. (Téllez-Plaza M, Navas-Acien A, Crainiceanu CM, Guallar E. Cadmium exposure and hypertension in the 1999-2004 National Health and Nutrition Examination Survey (NHANES). Environ Health Perspect. 2008;116(1). 